\title{
POR UMA EPISTEMOLOGIA DA ESPERANÇA: PAUL RICOEUR E O HORIZONTE DE PENSAMENTO NA FILOSOFIA E NA TEOLOGIA
}

Towards an Epistemology of Hope: Paul Ricoeur and the Horizon of Thought in Philosophy and Theology

Adriani Milli Rodrigues *

RESUMO: O distanciamento da teologia e da filosofia é normalmente marcado pela distinção entre fé e razão. Paul Ricoeur não ignora as diferenças epistemológicas dessas duas formas de pensamento, mas propõe, perspicazmente, que a relação entre razão e fé seja precedida pelo relacionamento entre razão e esperança. A esperança constitui o ponto de aproximação entre essas duas áreas, na medida em que ela se projeta como horizonte da investigação teológica e filosófica. Portanto, o presente artigo objetiva articular os traços fundamentais dessa perspectiva da esperança como horizonte teológico e filosófico. De forma geral, o horizonte da esperança reafirma os limites da razão na teologia e na filosofia, mas também ressalta possibilidades que se revelam nesse reconhecimento.

PALAVRAS-CHAVE: Esperança. Teologia. Filosofia. Epistemologia. Ricoeur.

ABSTRACT: The difference between theology and philosophy is usually marked by the distinction between faith and reason. Paul Ricoeur does not ignore this epistemological difference between these two schools of thought, but he insightfully proposes that the connection between reason and faith must be preceded by the relationship between reason and hope. Hope represents the point of encounter between these two areas of thoughts in the way that it portrays the scope of theological and philosophical investigation. Therefore, the present article aims to articulate the basic components of this perspective of hope as a theological and

* Centro Universitário Adventista de São Paulo, São Paulo, Brasil. 
philosophical horizon. Overall, the scope of hope does not only reaffirm the limits of reason in theology and philosophy, but also highlights the possibilities of reasoning, which emerged through this encounter between theology and philosophy.

KEYWORDS: Hope. Theology. Philosophy. Epistemology. Ricoeur.

\section{Introdução}

A esperança é um tema central no pensamento de Paul Ricoeur. O teóloIgo norte-americano Kevin Vanhoozer, que em seus estudos doutorais na Universidade de Cambridge se debruçou no pensamento filosófico de Ricoeur, costuma se referir ao pensador francês como "filósofo da esperança" (VANHOOZER, 2005; 1990, p. 6). Vanhoozer (1990, p. 6) identifica na filosofia de Ricoeur "uma paixão pelo possível", tendo em vista que a intuição central de sua filosofia postula que a existência humana é repleta de significado. Com efeito, a filosofia antropológica de Ricoeur foi positivamente influenciada por Gabriel Marcel, que utiliza como ponto de partida de sua reflexão filosófica a experiência da esperança, do amor, da fidelidade e da alegria, em contraste com reflexões existencialistas que iniciam suas análises a partir da experiência da ansiedade e da angústia (VANHOOZER, 1990, p. 15-18).

De fato, Marcel (1963, p. 37-86) procura delinear uma fenomenologia e uma metafísica da esperança, cujos contornos parecem se refletir no pensamento de Ricoeur (BOURGEOIS, 2006, p. 421-433; PORÉE, 2006, p. 329-349; BOURGEOIS, 2011, p. 119; BEATO, 2014, p. 113-137). Conforme Patrick Bourgeois, do departamento de filosofia da Universidade Loyola (New Orleans), destaca, "a compreensão da esperança e a imaginação central da filosofia de Paul Ricoeur oriunda de sua adaptação do entendimento da esperança em Kant e em Marcel" (BOURGEOIS, 2011, p. 119). Para ser mais preciso, Ricoeur "incorpora uma visão quasi-marceliana de esperança dentro de sua própria adaptação da antropologia filosófica kantiana" (BOURGEOIS, 2011, p. 119).

Em Paul Ricoeur on Hope, que representa provavelmente uma das investigações mais detalhadas do tema da esperança na filosofia ricoeuriana, Rebecca Huskey, do departamento de letras clássicas da Universidade de Oklahoma, procura desenvolver a tese de que a esperança é o tema central norteador da hermenêutica de Ricoeur, tanto no sentido estrito da interpretação textual como no sentido mais amplo da compreensão da "existência humana como um todo" (HUSKEY, 2009, p. 5). No entanto, uma das dificuldades encontradas por aqueles que pretendem articular uma filosofia da esperança se relaciona com o fato de que discursos sobre a esperança são em grande medida teológicos, isto é, se situam fora do campo específico da filosofia (BOURGEOIS, 2004, p. 28-41). 
É precisamente a tentativa de superação dessa dificuldade que constitui para Stewart (1970, p. 33-34) uma das principais contribuições do pensamento de Ricoeur, que desenvolve o conceito de esperança no nível de categoria filosófica. Stewart (1970, p. 44), no entanto, não interpreta essa empreitada ricoeuriana como uma ameaça para a teologia, como se o conceito de esperança corresse o risco de perder seu status teológico em um possível conflito entre os campos da filosofia e da teologia. Antes, a esperança se estabelece como conceito fronteiriço para a investigação filosófica e teológica. De fato, em vez de ameaça, Stewart (1970, p. 50) advoga que uma articulação filosófica da esperança enriquece a reflexão de uma teologia da esperança, sem necessariamente desconsiderar as diferenças e especificidades epistemológicas da filosofia e da teologia.

Tendo em vista esse útil vislumbre introdutório do tema da esperança em estudiosos da obra de Ricoeur, ${ }^{1}$ considerando particularmente a relação desse tema com os campos da filosofia e da teologia, o presente artigo pretende explorar a esperança como horizonte filosófico e teológico em Ricoeur. Por conta da imperativa necessidade de se delimitar o escopo do presente estudo sobre a temática da esperança, tendo em vista a abundante produção literária do filósofo em questão, este estudo privilegiará os artigos Hope and Structure of Philosophical Systems (RICOEUR, 1970, p. 55-69) e La liberté selon l'espérance ${ }^{2}$ (RICOEUR, 1969, p. 393-416). Ao passo que esses textos tenham sido publicados em inglês e em francês, respectivamente, utilizaremos para citações em português no corpo texto as traduções $A$ esperança e a estrutura dos sistemas filosóficos (RICOEUR, 2017, p. 101-116) e A liberdade segundo a esperança (RICOEUR, 1988b, p. 391-414).

A discussão desse artigo se organizará em três seções principais. A primeira procura introduzir elementos que colaboram para a compreensão do tema da esperança em Ricoeur. Essa seção se inicia com um delineamento dos traços fundamentais da fenomenologia e metafísica da esperança em Gabriel Marcel, que dada a sua influência na reflexão ricoeuriana, como mencionada acima, promove uma melhor apreciação da reflexão da esperança em Ricoeur. Em seguida, serão brevemente esboçados alguns traços do tema da esperança em Ricoeur, onde a realidade temporal humana e a existência do mal são conceitos centrais.

A segunda seção se concentrará na reflexão epistemológica da esperança que emerge dos textos Hope and Structure of Philosophical Systems e La liberté

\footnotetext{
${ }^{1}$ A temática da esperança em Ricoeur é explorada por vários estudos, tais como: Huskey (2009, p. 1-206), Bourgeois (2006, p. 421-433), Vanhoozer (2005, p. 27-28), Albano (1986, p. 77-88), Tiaha (2017, p. 457-459), Pacheco (2017, p. 217-258) e Einsohn (2014, p. 133-161).

${ }^{2}$ Esse texto foi publicado inicialmente em 1968 com o título "Approche philosophique du concept de liberté religieuse" em L'Herméneutique de la liberté religieuse, Actes du Congrès international Rome, janvier 1968, Archivio di Filosofia, direction E. Castelli, 38, 1968, et Aubier, Paris, 1968, p. 215-234.
} 
selon l'espérance. Por sua vez, a partir dos subsídios teóricos apresentados nas duas primeiras seções, a terceira seção procurará articular, de forma sucinta, uma perspectiva epistemológica da esperança, que sirva como horizonte para o pensamento filosófico e teológico.

\section{Elementos introdutórios para a compreensão da esperança em Ricoeur}

Como já indicado acima, a presente seção objetiva introduzir pontos que auxiliam no entendimento do tema da esperança em Ricoeur. Para tanto, a seção se divide em duas partes. A primeira descreve traços fundamentais da fenomenologia e metafísica da esperança em Marcel, com foco na palestra realizada por ele na Scolasticat de Fourvière em fevereiro de 1942, intitulada Esquisse d'une phénoménologie et d'une métaphysique de l'espérance (MARCEL, 1963, p. 37-86). ${ }^{3}$ A seguir, a segunda parte indica, de forma sucinta, traços do tema da esperança em Ricoeur, levando em conta os temas centrais da realidade temporal humana e da existência do mal no pensamento ricoeuriano.

\subsection{Traços da fenomenologia e metafísica da esperança em Marcel}

A reflexão de Marcel (1963, p. 37-86) sobre a esperança em Esquisse d'une phénoménologie et d'une métaphysique de l'espérance é marcada por contrastes e descrições que procuram elaborar o que a esperança é, e o que ela não é. Em termos de contrastes, a esperança não é mero otimismo, e nem gera mera complacência com uma situação vigente. Marcel (1963, p. 7374) também contesta a ideia de que a esperança seria mera subjetividade, e de que a evidência da experiência da realidade deveria esvaziar esse sentimento subjetivo que pertenceria ao mundo das miragens (MARCEL, 1963, p. 69). Todavia, ele reconhece que a esperança pode sofrer os efeitos da degradação. Exemplos de degradação incluem a esperança enquanto mera expectativa passiva, de um lado, e a expectativa que demanda seus 'direitos' de uma nova realidade, de outro.

Positivamente, Marcel (1963, p. 40) descreve a esperança como a atitude humana que "se volta para a luz que ainda não vê, para uma luz

\footnotetext{
${ }^{3}$ Embora essa seja a primeira reflexão elaborada e específica de Marcel sobre a esperança, ela certamente não é a única. Como O'Callaghan (1989, p. 55n1) destaca, os textos mais importantes de Marcel com relação à temática da esperança incluem: Esquisse d'une phénomenologie de d'une metaphysique de l'Espérance (1942), La Structure de l'Espérance (1951), Le Désir et l'Espérance (1963). Para comentários úteis acerca da esperança em Marcel, veja Santos (1965, p. 380-401); Bertman (1970, p. 101-105); Plourde (1975, p. 1-232); (Godfrey (1987, p. 103-132); Freitas (1989, p. 531-548); O'COLLANGHAN (1989, p. 55-92); Hernandez (2011, p. 1-137).
} 
a nascer, na esperança de ser liberta de sua noite presente, a noite da espera" ${ }^{\prime \prime}$. A compreensão da esperança por meio da metáfora de expectativa do surgimento da luz, no contexto do cativeiro da condição humana na noite escura, necessita, no entanto, ser diferenciada de um mero otimismo. De fato, o autor parece situar o otimismo no nível superficial das palavras. Para ele, "o otimista é essencialmente um tagarela" (MARCEL, 1963, p. 44).

Além disso, a esperança da luz radiante não se traduz em termos de mera aceitação da noite sombria, mas ela também não trata a noite com o sentimento de revolta. Ao invés dos polos de aceitação ou revolta, a atitude de não aceitação tomada pela pessoa de esperança se caracteriza fundamentalmente pela paciência. Na ótica de Marcel (1963, p. 52), a paciência pode sofrer a degradação de se tornar fraqueza e complacência, mas isso ocorre quando ela perde o seu princípio essencial, a saber, a caridade. Tal princípio permite que o autor desenvolva uma perspectiva da paciência em termos de altruísmo, que evita uma concentração individualista, egoísta. Por meio da mola propulsora da caridade, a paciência evita as iniciativas de violência com relação ao tempo e ao ritmo do outro. Mais especificamente, a violência impaciente ignora o ritmo autônomo do outro e procura forçá-lo a se curvar aos seus próprios interesses, ao seu próprio ritmo. Assim, por meio da caridade a paciência respeita o ritmo diferente da alteridade, permitindo "um certo pluralismo temporal" (MARCEL, 1963, p. 51). No entanto, quando a paciência não é movida pela caridade, ela se transforma inadequadamente em mera fraqueza e complacência. Portanto, ao elaborar o conceito de paciência, Marcel procura evitar os extremos da violência, enquanto ausência de paciência, bem como da complacência, que representa a deterioração da paciência.

A preocupação com os extremos também marca a abordagem de Marcel em relação à esperança, a mera expectativa e a demanda obrigatória. Por um lado, a mera expectativa passiva representa a deterioração da esperança. Como exemplo, o mero expectador não está envolvido dentro do jogo que assiste, mas apenas torce externamente pela vitória de um dos competidores (MARCEL, 1963, p. 52). Logo, a simples expectativa passiva e externa não constitui a esperança em seu sentido genuíno, mas deteriorado. Além disso, há uma outra possibilidade de deterioração da esperança, e esse outro tipo de problema é elaborado por meio da noção de contrato. Marcel (1963, p. 70) argumenta que o desapontamento assume uma relação contratual. Na medida em que alguém cria uma expectativa, ele dá algo de si mesmo. Mais precisamente, ele dá crédito. Todavia, por alguma razão misteriosa, o evento ou sua causa não cumpre as consideradas obrigações de reciprocidade para com essa pessoa. Assumindo

\footnotetext{
${ }^{4}$ Todas as traduções de citações neste artigo seguem tradução livre.
} 
que essa é uma descrição adequada da situação de desapontamento, é precisamente a estrutura de relacionamento contratual que permite que o desapontamento aconteça.

Mas Marcel advoga que, em contraste com a estrutura e a situação de desapontamento, a esperança genuína nunca assume uma relação contratual com a realidade. Essa é, com efeito, a "dignidade soberana" da esperança, visto que ela não reivindica nem reclama seus direitos (MARCEL, 1963, p. 70). Se Marcel discute o conceito de paciência à luz do princípio da caridade, similarmente, ele elabora o tema da esperança em relação ao princípio do amor, que se expressa por meio da dádiva da graça. A espera por uma dádiva ou favor de outro se fundamenta na graça da liberalidade, e não tem nada que ver com uma expectativa de obrigação. Nessa perspectiva, "na raiz da esperança, há algo que nos é literalmente oferecido; mas nós podemos rejeitar a esperança" assim como nós podemos rejeitar "o amor" (MARCEL, 1963, p. 80). Assim, Marcel (1963, p. 85) pressupõe que há uma "indissolúvel conexão que liga a esperança e a caridade". Ao pensar a esperança enquanto dádiva amorosa e graciosa, o autor parece evitar tratá-la como mera projeção da subjetividade, traçando um quadro em que algo é oferecido à pessoa para que ela possa observar os fatos mais imediatos e transcendê-los, de modo que não haja conformidade em relação a eles e nem uma demanda de mudança, mas uma projeção apreciativa de que algo novo vai surgir no horizonte, e tal projeção é uma dádiva a ser abraçada.

Se a dádiva da esperança permeia a vida como um todo, ela se faz presente no que Marcel $(1963$, p. 55) denomina de triangulação que realizamos a cada momento da nossa existência, a saber, a "relação entre o imediato, o antecipado e também a lembrança". Nessa triangulação, o antecipado é iluminado pela dádiva da esperança, e lança luz ou se relaciona positivamente com o momento imediato e a memória lembrada. Curiosamente, essa triangulação temporal é particularmente elaborada por Ricoeur, em sua compreensão da realidade temporal humana em seu caráter temporal.

\subsection{Esperança e a realidade temporal humana}

Uma compreensão adequada da noção de esperança em Ricoeur requer uma perspectiva da experiência de temporalidade (HUSKEY, 2009, p. 5; VANHOOZER, 1990, p. 15-18). Considerando a profunda relação entre tempo e narrativa, o filósofo francês desenvolve a ideia de que a vida humana se caracteriza pela identidade narrativa (RICOEUR, 1986b, p. 55-695;

\footnotetext{
${ }^{5} \mathrm{O}$ texto Life: A Story in Search of a narrator (RICOEUR, 1986b) foi publicado posteriormente em francês como La vie: un récit en quête de narrateur. In: GOLDENSTEIN, C.; SCHLEGEL, J.L.; DELBRACCIO, M. (Orgs.). Ecrits et conférences. Paris: Le Seuil, 2008. t. 1. p. 257-276.
} 
RICOEUR, 1988a, p. 295-304). Um bom exemplo da discussão da realidade narrativa/temporal da vida humana se encontra em Temps et récit, cujas citações diretas colocadas abaixo no corpo do texto seguem a tradução em português de Tempo e narrativa (RICOEUR, 1994, p. 19-54).

Em seu primeiro capítulo de Temps et récit, Ricoeur (1983, p. 19-54) discute as aporias da experiência do tempo, em diálogo com o livro XI das Confissões de Agostinho. Nesse capítulo, a temporalidade é discutida enquanto experiência psicológica, particularmente no contexto da narração. Aliás, a obra narrativa expressa "o caráter temporal da experiência humana" (RICOEUR, 1994, p. 15). Nessa estreita relação entre temporalidade e narrativa, "o tempo torna-se tempo humano na medida em que está articulado de modo narrativo" e "a narrativa é significativa na medida em que esboça os traços da experiência temporal" (RICOEUR, 1994, p. 15). Com efeito, se o tempo é humano enquanto articulado de modo narrativo, o ato de narrar não pertence apenas ao trabalho literário, mas primariamente à própria experiência inteligível da vida humana. Pensar a experiência da vida significa reunir ou sintetizar narrativamente a heterogeneidade de "intriga, objetivos, causas, acasos" da experiência humana "sob a unidade de uma ação total e completa" (RICOEUR, 1994, p. 9-10). Obviamente, o labor literário tem o potencial de tornar esses traços narrativos do pensamento ainda mais marcantes por meio da elaboração mais profunda da linguagem.

No pensamento narrativo de síntese, há uma ação cognitiva tríplice, muito semelhante à ideia de triangulação em Gabriel Marcel mencionada na seção anterior, que se configura pelos tempos passado, presente e futuro. Em diálogo com Agostinho, Ricoeur (1994, p. 39) denomina cognitivamente esses tempos como memória (passado), atenção (presente) e espera (futuro). $\mathrm{Na}$ medida em que a narrativa avança, a espera ou expectativa diminui e a memória se alonga. Curiosamente, na experiência psicológica humana essa tríplice ação cognitiva ocorre no presente. Nas palavras do pensador francês, há uma interação de um "tríplice presente: entre o presente do futuro, o presente do passado e o presente do presente", visto que "os desígnios da expectativa, da atenção e da memória" se articulam psicologicamente no momento presente (RICOEUR, 1994, p. 41). Nesse sentido, ele conclui que "o que se mede não são as coisas futuras ou passadas, mas sua espera e sua recordação" (RICOEUR, 1994, p. 40).

À luz dessa reflexão temporal ou narrativa, a esperança se configura psicologicamente por uma projeção presente acerca de uma expectativa de ocorrência no futuro. Assim, o momento presente se caracteriza pela espera, que interage cognitivamente com a memória acumulada e com a atenção em relação aos eventos atuais. A rigor, não há necessariamente nessa reflexão temporal ou narrativa uma qualificação do que se espera, indicando se a expectativa tem tom otimista ou pessimista. A esperança, 
enquanto espera de tom otimista, é esboçada na discussão abaixo sobre a esperança e a realidade do mal.

\subsection{Esperança e a realidade do mal}

A filosofia de Ricoeur se atenta à realidade problemática do mal na vida humana. Uma de suas principais obras nessa temática é La symbolique du mal (1960). Nessa obra ele utiliza imagens similares às usadas por Marcel, em termos de luz que ainda não se vê na escuridão da noite, para se referir à esperança. No contexto de sua discussão sobre a sabedoria babilônica, Ricoeur (1986c, p. 316) menciona a esperança como raio de luz na escuridão da angústia. Além disso, o filósofo francês comenta a questão da expectativa de julgamento, no sentido de justa punição, e enfatiza a esperança de que o temor desaparecerá da consciência (RICOEUR, 1986c, p. 44). Por sua vez, ao comentar a imagem bíblica do julgamento escatológico, em conexão com o conceito do perdão da culpa em dimensão cósmica e coletiva (ao invés de meramente subjetiva e individualista), ele fala da esperança no sentido de "tensão temporal" (RICOEUR, 1986c, p. 276). No contexto, da narrativa israelita de Abraão, a esperança se relaciona com a promessa da terra, e para o pensamento judaico-cristão a esperança de um mundo ideal, precedido pelo julgamento, pode ser vislumbrado pelo "olho da esperança" que enxerga "o significado da salvação vindo do futuro para o presente" (RICOEUR, 1986c, p. 262-263).

Outra discussão significativa que contrasta o olhar da esperança com uma situação problemática que precisa ser superada se encontra nos comentários de Ricoeur acerca da lamentação como prece, na coleção de ensaios com André LaCocque em Penser la Bible (1998). Mais especificamente, o mal ou situação problemática que figura nessa discussão é a questão do sofrimento. Ao passo que o foco das reflexões de Ricoeur nesse texto se situe nos gritos de angústia do Salmo 22, ele também dialoga com os profetas maiores da Bíblia Hebraica. O filósofo francês argumenta que "para um Isaías, um Jeremias e mesmo um Ezequiel, a retirada de Deus permanece o contexto para a luta contra a ocultação. Essa luta é o que realmente está em jogo em seu sofrimento" (RICOEUR, 2001, p. 247). Nesse sentido, a pregação profética "de um Deus oculto permanece uma luta por manifestação" (RICOEUR, 2001, p. 247). Contudo, a luta que se instaura nessa situação de sofrimento se depara com uma realidade paradoxal: é precisamente "nas profundezas da rejeição" divina "que a salvação é esperada" (RICOEUR, 2001, p. 247). Ricoeur (2001, p. 248) observa essa situação especialmente nos poemas do servo sofredor e afirma que, nessa "teologia do paradoxo", a esperança se situa particularmente "nas próprias profundezas do infortúnio".

Em La mémoire, l'histoire, l'oubli (2000), o pensador francês associa a esperança futura com o mal presente ou uma situação problemática corrente, 
mas também às boas memórias do passado. Nesse sentido, a esperança futura se conecta com a negativa angústia presente, e também com a positiva nostalgia do passado (RICOEUR, 2007, p. 167). Obviamente, uma elaboração dessa associação projetaria a esperança em tons de superação da angústia presente e retorno de aspectos da realidade nostálgica do passado.

Nas suas palestras sobre ideologia e utopia apresentadas na Universidade de Chicago em 1975, o filósofo francês salienta que o pensamento iluminista moderno não se atentava para a problemática da limitação racional humana. Ao comentar o posicionamento de Habermas, Ricoeur (1986a) enfatiza que, de acordo com o filósofo alemão, o iluminismo advogava "a racionalidade da utopia", que objetivava a "promoção de uma esperança racional". Certamente, esse comentário não trata diretamente da questão do mal. No entanto, ele se alinha à compreensão de que, em seu projeto moderno de sociedade marcado pelo otimismo de progresso das potencialidades humanas, o iluminismo possuía uma percepção inadequada da realidade do mal no mundo e das limitações da racionalidade humana. Tal percepção inadequada permitia a elaboração de uma esperança racional.

É notório que as breves menções à esperança indicadas nessa seção não representam uma elaboração desenvolvida do conceito de esperança em Ricoeur, especialmente quando o conteúdo dessa seção é comparado com outras seções do presente artigo. Todavia, para usar a linguagem de Marcel, esses recortes evidenciam como a realidade do mal (mesmo quando percebida de forma limitada/inadequada) constitui a noite, na qual se espera a luz que ainda não se vê. Nesse sentido, as trevas da noite são caracterizadas particularmente pela angústia, pelo temor, pela culpa, pelo sofrimento e pelo infortúnio. Contudo, Ricoeur não deseja elaborar epistemologicamente a esperança, a expectativa do brilho da luz em meio a essas trevas da experiência humana, nos termos de uma racionalidade lógica e ingenuamente otimista. Isso fica evidente na discussão abaixo acerca de uma perspectiva epistemológica da esperança.

\section{Uma perspectiva epistemológica da esperança em Ricoeur}

Nessa seção, a descrição da perspectiva epistemológica da esperança em Ricoeur não tem a pretensão de exaustividade, mas se concentra em dois textos fundamentais onde a reflexão do pensador francês acerca da epistemológica da esperança emerge: Hope and Structure of Philosophical Systems e La liberté selon l'espérance. Os dois textos têm conteúdos similares, que não serão meramente repetidos nas descrições individuais dessa seção, para evitar a duplicação desnecessária de elaborações argumentativas. A seção 
se inicia com Hope and Structure of Philosophical Systems, que apresenta os traços principais dessa epistemologia, especialmente na elaboração filosófica. A seguir, a seção abordará La liberté selon l'espérance, que oferece maior detalhamento epistemológico no campo da teologia, quando comparado com a abordagem de Hope and Structure of Philosophical Systems. Assim, a leitura conjunta desses textos será fundamental para o estabelecimento dos subsídios teóricos para a articulação construtiva prevista para a próxima seção.

\subsection{A esperança e a estrutura dos sistemas filosóficos}

Em Hope and Structure of Philosophical Systems, Ricoeur (1970, p. 55-69) claramente elabora a espera ou a expectativa em tom otimista, mas procurando evitar um otimismo ingênuo. Primeiramente, ele reconhece que a esperança é um conceito eminentemente teológico. Somente após esse reconhecimento o filósofo irá articular o papel da esperança na filosofia. Como virtude teologal, a esperança se relaciona positivamente com a fé e o amor. Os contornos otimistas da esperança no contexto teológico se expressam pela expectativa escatológica do reino de Deus, conforme enfatizada na teologia da esperança de Jürgen Moltmann, a noção de cumprimento da promessa divina e a afirmação da ressurreição. Nas palavras de Moltmann (2005, p. 33-34), “a esperança cristã é esperança de ressurreição", visto que as "afirmações de esperança" contradizem nossa experiência presente "de sofrimento, mal e morte".

Em diálogo com Kierkegaard, Ricoeur (2017, p. 105) fala da esperança em termos de "paixão pelo possível". Se a esperança parece em um primeiro momento "irracionalidade" ou "lógica absurda", ele procura indicar que ela constitui, em realidade, um outro tipo de racionalidade. Utilizando a linguagem bíblica de Paulo em Romanos 5, o filósofo francês advoga que a "nova lógica da esperança [...] atravessa a lógica do pecado" (RICOEUR, 2017, p. 104). Enquanto o crime e a punição se expressam pela "lógica de equivalência ('o salário do pecado é a morte')", a "esperança é uma lógica de acréscimo e de superabundância ('onde abundou o pecado, a graça superabundou')" (RICOEUR, 2017, p. 105). Assim, a lógica da "esperança representa a superabundância da significação em oposição à abundância do não-sentido, do fracasso e da destruição" (RICOEUR, 2017, p. 105). Nessa lógica, a paixão pelo possível é a resposta da esperança à triste meditação da fatalidade de um destino que parece irrevogável.

No entanto, Ricoeur ressalta que o otimismo da esperança ou a paixão pelo possível não deriva de uma ilusão ingênua. Não há aqui uma negação da realidade. A ressurreição não olvida o passado da cruz. A ressurreição é precisamente uma ressurreição dos mortos. Assim, a esperança não é uma negação ingênua da realidade da morte, mas uma negação que projeta a 
sua superação. Como tal, "essa negação repousa sobre sinais, não sobre provas. Interpreta de uma maneira criativa os sinais da superabundância da vida a despeito da evidência da morte" (RICOEUR, 2017, p. 105). Para Ricoeur (2017, p. 105), "o 'tanto mais' da lei da superabundância não pode abrir mão do 'a despeito de', a despeito da morte, que dá à esperança sua lucidez, sua seriedade, sua determinação". Portanto, de acordo com a lógica da esperança, é possível "viver segundo a lei paradoxal da superabundância, da negação da morte e da afirmação do excesso de sentido sobre o não-sentido em todas as situações desesperadas" (RICOEUR, 2017, p. 105).

Esse novo tipo de racionalidade da lógica da esperança (intellectus spei) se assemelha à racionalidade da fé (intellectus fidei). Aliás, devemos nos lembrar que o filósofo francês reconhece que a esperança é uma virtude teologal que se relaciona com a fé e o amor. Ricoeur chega a utilizar a expressão intellectus fidei et spei. Todavia, ele também procura delinear uma distinção entre a epistemologia da esperança e a epistemologia da fé. Seu interesse com essa distinção é prover uma perspectiva epistemológica que seja capaz de estabelecer um diálogo mais profícuo entre a teologia e a filosofia.

O filósofo francês argumenta que o intellectus fidei não é capaz de promover o diálogo desejado. Ele indica que a racionalidade da fé se distingue da racionalidade filosófica, visto que a fé não é parte da epistemologia filosófica. Por outro lado, Ricoeur propõe que a esperança é capaz de exercer um papel efetivo na epistemologia filosófica. Por isso, o filósofo francês prefere falar primeiramente do intellectus spei ao tratar da relação entre a teologia e a filosofia. Ao colocar a discussão da esperança antes da questão da fé, Ricoeur (2017, p. 101) busca deslocar a problemática "no confronto entre a filosofia e a teologia". É preciso destacar, no entanto, que, com esse deslocamento, o filósofo francês não procura primariamente inserir a temática da esperança como objeto da reflexão filosófica. Antes, seu objetivo é promover uma uma mudança na organização estrutural do sistema ou discurso filosófico.

Ricoeur (2017, p. 102) sugere que essa mudança organizacional não pode ser realizada se a esperança for meramente um elemento material da reflexão filosófica, isto é, um objeto de discussão. Nesse sentido, a problemática da esperança deve ser vista como elemento formal ou estrutural da epistemologia filosófica. Em termos estruturais, o filósofo francês destaca o ponto de partida e o ponto de chegada do discurso ou sistema filosófico. Do mesmo modo como é necessário discutir a problemática do ponto de partida do discurso filosófico, conforme sublinham Descartes e Husserl, Ricoeur (1970, p. 102) ressalta a necessidade de se discutir o ponto de chegada, o encerramento ou a finalidade do discurso filosófico. É nessa perspectiva teleológica da estrutura dos sistemas filosóficos que o filósofo 
francês advoga que a esperança deve ser o horizonte de encerramento do discurso filosófico.

É possível inferir da argumentação de Ricoeur que, na perspectiva de uma estrutura epistemológica, o intellectus fidei (a lógica da fé) se situa no ponto de partida da reflexão, ao passo que intellectus spei (a lógica da esperança) é o horizonte final da reflexão. Com base nessa inferência, o filósofo francês parece deslocar a ênfase do intellectus fidei para o intellectus spei para pensar a relação entre a teologia e a filosofia porque ele vislumbra um cenário onde esses dois campos do saber tenham um horizonte epistemológico comum, embora seus pontos de partida sejam diferentes, visto que a reflexão teológica se inicia com o intellectus fidei. Ao passo que a fé, enquanto ponto de partida, busca compreensão, a esperança, enquanto horizonte, aguarda a compreensão. Para usar a linguagem de Ricoeur (2017, p. 106), "spero ut intelligam: espero para compreender". A espera é necessária porque a paixão pelo possível é lúcida, não ilusória. Ao invés de um otimismo ingênuo, a esperança tem uma conduta paradoxal: reconhecer a evidência da morte e a lógica da ausência de sentido, mas ainda vislumbrar na vida sinais da superação da morte e a existência da lógica da superabundância de sentido. Nesse paradoxo, no horizonte da esperança aguardamos a compreensão. Como White (1991, p. 320) sublinha, a hermenêutica ricoeuriana expressa a esperança de uma melhor compreensão, sem a supressão da suspeita vigilante. Paradoxalmente, o horizonte da esperança é capaz de envolver a suspeita.

O horizonte da esperança ou da paixão pelo possível pode ser articulado teologicamente. Segundo a indicação de Ricoeur, a discussão teológica da esperança em Moltmann seria um exemplo dessa articulação. Mas como esse horizonte poderia ser articulado na filosofia? Uma resposta adequada à essa pergunta exigiria um estudo específico dessa questão. Contudo, é possível indicar brevemente aqui os traços gerais da proposta do filósofo francês. Ricoeur utiliza os sistemas hegeliano e kantiano como dois tipos de estruturas filosóficas que auxiliam a visualização da adequação ou inadequação do horizonte da esperança em um sistema filosófico. Embora ele reconheça virtudes no tipo hegeliano e identifique importantes corretivos desse sistema para o tipo kantiano, a filosofia de Hegel tem como horizonte o saber absoluto. Nas palavras de Ricoeur (2017, p. 107), o sistema de Hegel "é um sistema escrito do fim para o começo, a partir do ponto de vista da totalidade [...] E esse fim não é algo que poderia ser aguardado ou esperado: é o eterno presente do pensamento, que sustenta a história do pensamento". Como "filosofia da reminiscência", onde a "racionalidade pertence ao todo como presente" o tipo de sistema hegeliano do saber absoluto é contrário à filosofia da esperança.

Com efeito, a filosofia da esperança se aproxima do sistema kantiano, que se caracteriza como "a filosofia dos limites". Embora a razão exija, em um 
primeiro momento, a totalidade do conhecimento, ela se confronta com impossibilidade dessa exigência. Ricoeur (2017, p. 111) toma as três questões de Kant no Opus postumum como uma estrutura sequencial inseparável para um sistema filosófico: "Que podemos saber? Que devemos fazer? Que temos o direito de esperar?" Uma descrição adequada da estrutura do sistema que ele vislumbra com essas três perguntas extrapola os limites desse artigo, mas uma questão pode ser elucidada: a relação entre o saber e o esperar, que envolve a primeira e a terceira pergunta. Para o filósofo francês, "se não começarmos pela primeira crítica", a do conhecimento, "perdemos algo de essencial de uma filosofia da esperança, a saber, a destruição do saber absoluto" (RICOEUR, 2017, p. 111). Nesse sentido, "a razão deve primeiro desesperar, desesperar do absoluto, desesperar dela mesma [...] Mas o desespero, na Crítica da razão pura, não é um sentimento, uma emoção: é um processo, uma operação, o ato positivo de colocar um limite à pretensão da inteligência" (RICOEUR, 2017, p. 111). Assim, esse ato cognitivo de renúncia ou desespero já é, em si, um ato de esperança. Nesse caso, a esperança não é um último tema que fecha, "mas um impulso que abre o sistema, que rompe o encerramento do sistema: é uma maneira de reabrir" estruturalmente "o que fora indevidamente fechado" (RICOEUR, 2017, p. 110). Na perspectiva da esperança, "o limite é um ato que abre", que rompe a ideia de chegada ou um pretenso ponto de encerramento e "abre um horizonte" (RICOEUR, 2017, p. 112).

Portanto, para Ricoeur, a esperança constitui o horizonte epistemológico adequado tanto para a investigação teológica, quanto para a reflexão filosófica.

\subsection{A liberdade segundo a esperança}

Em La liberté selon l'espérance, Ricoeur (1969, p. 393-416) distingue de forma mais clara as especificidades da elaboração teológica e da elaboração filosófica. Embora o filósofo francês creia que essas duas disciplinas devem ser aproximadas, ele busca delinear e defender uma clara distinção e certo distanciamento entre elas, para que a identidade peculiar de cada disciplina não seja ameaçada ou distorcida. No caso da teologia, a palavra-chave de sua identidade é o kerygma. Esse conteúdo da fé proclamado necessita ser articulado de acordo com o sistema conceitual que lhe é inerente. De modo que a teologia tenha seu próprio ângulo de enxergar a realidade, a fim de que o seu discurso tenha coerência interna, à luz do pano de fundo dos pressupostos formados pelas ideias que se expressam, explícita ou implicitamente, no kerygma da fé. No contexto da filosofia, o conceito primordial é a razão. Ricoeur advoga que a filosofia é uma reforma incessante do pensar dentro dos limites da razão somente, de acordo com suas exigências internas. Por conta desses limites, o relacionamento da filosofia com a teologia deve evitar os extremos da abstenção e da capitulação. No 
primeiro caso, há perigo de se evitar, desnecessariamente, uma discussão potencialmente enriquecedora de uma temática ou reflexão que tenha pontos em comum com teologia, especialmente quando o filósofo é religioso. Por outro lado, Ricoeur destaca o risco indevido de subordinação da filosofia em relação à teologia, de forma que os limites da razão exigidos na elaboração filosófica sejam desrespeitados e transgredidos.

A partir dessa notável advertência de distinção entre o fazer teológico e o filosófico, o filósofo francês explica a relação entre a esperança e o kerygma, visto que esse último é o elemento norteador do trabalho teológico. Em outras palavras, essa explicação retrata a esperança no contexto da teologia. De fato, Ricoeur explicita enfaticamente a sua apreciação por Moltmann com relação à teologia da esperança. Tal apreciação se refere, de forma particular, à visão escatológica do kerygma promovida pelo teólogo alemão. Essa visão privilegia a compreensão histórica da esperança, onde a promessa se constitui temporalmente. Nessa compreensão, cada cumprimento específico de uma promessa representa a confirmação da expectativa de uma promessa mais ampla, o que provê o momento adequado para a repetição dessa promessa. Com efeito, o filósofo francês contrasta a perspectiva temporal ou histórica da promessa com duas posturas que ele critica, a saber, a interpretação existencial da Bíblia e a correlata crença no primado da necessidade.

Em termos da interpretação existencial, Ricoeur menciona nomes como Kierkgaard e Bultmann, que objetivam promover a decisão existencial, e define essa interpretação como fundada na filosofia do eterno presente, que esvazia a dimensão escatológica. O filósofo francês identifica nesse esvaziamento prejuízos de ordem histórica, comunitária e cósmica, tendo em vista que a decisão existencial privilegia o indivíduo (em detrimento das dimensões comunitária e cósmica) e o agora (em detrimento da dimensão histórica do fluxo passado-presente-futuro). Ricoeur observa na história do pensamento ocidental movimentos e personalidades que promoveram, de diversos modos, a filosofia do eterno presente. De fato, o estoicismo grego é indicado como expressão mais desenvolvida da ética do presente. Em tempos modernos, a máxima de Espinoza "não espere, não temas" também enfatiza a primazia do presente. Além disso, as posturas de suspeita e desilusão promovida por pensadores como Nietzsche e Freud procuram formular uma sabedoria do presente. Em sua crítica à essas formas de filosofia do presente, o pensador francês destaca a antítese moltmanniana entre a religião da promessa e a religião da presença. Ao passo que a primeira privilegia a projeção futura, a segunda se alinha à interpretação bíblica existencial do agora.

Na perspectiva de Ricoeur, a filosofia do presente que norteia a interpretação existencial se vincula ao determinismo do primado da necessidade. Com isso, projeções acerca do futuro não se abrem para o poder do possível. 
De fato, o pensamento determinista se fecha para a imaginação criativa que tem a possibilidade de vislumbrar uma realidade que seja, de alguma maneira, diferente daquilo que se vê atualmente como ocupando um papel preponderante. Desse modo, o filósofo francês detecta uma oposição entre o pensamento da esperança, marcado pela paixão pelo possível, e o pensamento determinista da necessidade. Em outras palavras, o pensamento da esperança é uma contradição do primado da necessidade, preferindo um olhar para o futuro informado pela liberdade do possível, e não pelo determinismo do impossível.

Em linguagem teológica, Ricoeur fala do pensamento da esperança em termos da hermenêutica da ressurreição. Essa hermenêutica não se fecha para a promessa, mas se abre para o significado do futuro, que vislumbra "a morte da morte", isto é, a ressurreição dos mortos. A hermenêutica da ressurreição, no entanto, não constitui um pensamento otimista ingênuo que ignora os fatos de uma realidade cruel e desanimadora. À semelhança do que já foi indicado na discussão acima sobre $A$ esperança e a estrutura dos sistemas filosóficos, a hermenêutica da ressurreição se caracteriza por um pensamento dialético que não ignora a realidade do mal, mas o coloca em tensão com sinais de algo maior do que essa realidade. Assim, essa hermenêutica abarca dois polos, um negativo e outro positivo. No polo negativo está o reconhecimento da dura realidade da morte. No polo positivo, está a habilidade de decifrar sinais da ressurreição, mesmo no contexto da contrária aparência da morte. Nesse último polo, a hermenêutica da ressurreição detecta uma lógica do excedente da vida e de seu significado. Essa lógica permite que a hermenêutica da ressurreição não se defina meramente pela afirmação da vida "a despeito de" (da morte), mas pela afirmação de que ela se caracteriza pelo "muito mais", que excede a mera negação da primazia da realidade da morte.

Obviamente, a articulação de uma hermenêutica da ressurreição se situa no campo da reflexão teológica que, como o próprio Ricoeur salienta, não deve se misturar com a reflexão filosófica. Todavia, o pensador francês postula que uma aproximação entre as reflexões teológica e filosófica é possível e, até mesmo, desejável. De forma mais específica, o meio de aproximação adotado por Ricoeur se traduz pela busca de uma equivalência filosófica da discussão teológica da esperança. Assim, o pensador francês procura respeitar a jurisdição de cada disciplina, mas também tenta identificar equivalentes de uma perspectiva próxima ou comum entre elas, que são articulados em seus próprios termos. Mas antes de se lançar à busca de um equivalente filosófico, no trabalho de aproximação filosófica, é necessário esboçar os contornos básicos da lógica da reflexão teológica, que seria um trabalho de aproximação teológica. Desse modo, a aproximação ocorre no âmbito das duas disciplinas, sendo que a aproximação teológica inicial visa facilitar o processo de aproximação filosófica que vem em seguida. 
Em seu esboço básico da lógica da esperança no contexto teológico, Ricoeur observa no kerygma da esperança a realidade da inovação de sentido e uma demanda epistemológica de sua inteligibilidade. Nessa inovação ocorre uma abertura, isto é, a irrupção de uma ordem fechada. A busca de sua inteligibilidade envolve a negação da primazia da realidade da morte, que representa uma resposta da superabundância de sentido à abundância da ausência de sentido. Tal postura deriva do reconhecimento dos sinais da "nova criação", para usar uma linguagem teológica, de uma novidade que nos alcança. Nas palavras de Ricoeur, "a novidade do novo se faz explícito", em uma indefinida repetição de sinais. O filósofo francês diferencia, entretanto, a esperança que nasce da irrupção do novo e a elaboração da utopia. Em sua perspectiva, a esperança tem caráter particularmente epistemológico. A esperança faz pensar, desenvolvendo sua própria lógica. Em outras palavras, a esperança envolve um novo modo de pensar.

De maneira similar ao que foi indicado em $A$ esperança e a estrutura dos sistemas filosóficos, a opção escolhida por Ricoeur para traçar uma aproximação filosófica é o kantianismo. Contudo, seu interesse no pensamento kantiano não se expressa meramente em termos de uma repetição das ideias de Kant, mas a construção de uma perspectiva filosófica que se abre para o horizonte da esperança. Dito de outro modo, Ricoeur enxerga no kantianismo os recursos conceituais de base para a elaboração de sua perspectiva da esperança. Entendendo o kantianismo como uma filosofia dos limites, e não de sistema (como em Hegel), o filósofo francês considera que a esperança, no contexto do pensamento kantiano, exerce um poder de fissura em sistemas filosóficos fechados, que tem o poder de reorganizar o sentido. No contexto da crítica da razão pura, a ideia de limites é especialmente marcante. Todavia, no contexto da crítica à razão prática, há uma demanda de totalidade que não é dada, mas pressuposta como necessária e esperada. Aqui se encontra no pensamento kantiano, conforme elaborado por Ricoeur, a conexão entre moralidade e felicidade, na qual há uma síntese transcendente de dois elementos distintos. Essa síntese, no entanto, não é dada, mas pedida e esperada. O caráter transcendental dessa síntese a distingue das concepções gregas, mais especificamente epicuristas ou estoicas, de felicidade. Na síntese transcendental, diferente da moralidade, a felicidade não é resultado imediato de nossa própria ação. Antes, a felicidade é alcançada como superadição, como elemento excedente. Essa compreensão se relaciona particularmente com a questão de Kant sobre "o que eu posso esperar", que se situa na sua abordagem racional da esperança na discussão da religião nos limites da razão simples. Ricoeur (1988b, p. 406) realça a peculiaridade de Kant nessa abordagem específica ao confessar: "que eu saiba nenhum outro filósofo definiu exclusivamente a religião através desta questão". 
O pensador francês explica que a dialética da liberdade em Kant se formula pelo dever e pela autonomia, onde o sujeito autônomo que busca cumprir o seu dever (moralidade) postula, na perspectiva da razão prática, a existência do bem (felicidade). Nesse sentido, a liberdade caminha na direção da esperança. Mas esse alvo da razão prática, como dito, é uma superadição e não um resultado direto da ação moral. A razão prática "exige a completude; mas ela crê, à maneira da espera, da esperança, na existência de uma ordem onde completude pode ser efectiva" (RICOEUR, $1988 b$, p. 409). É nesse contexto que Ricoeur sublinha a expectativa kantiana da imortalidade, a expectativa do bem que supera a morte. Como o filósofo francês comenta, "este 'progresso indo até ao infinito', não está no nosso poder; nós não podemos no-lo dar, apenas podemos 'encontrá-lo'". Assim, "o postulado da imortalidade exprime a face de esperança do postulado da liberdade" (RICOEUR, 1988b, p. 409). Na interpretação ricoeuriana da mediação entre filosofia e teologia, a indicação katiana da "continuação e [...] persistência indefinida da existência é o equivalente filosófico da esperança da ressurreição". Aliás, Kant nomeia essa crença como "espera - Erwartung" (RICOEUR, 1988b, p. 409). À luz desses conceitos, Ricoeur (1988b, p. 409) sintetiza epistemologicamente o horizonte da esperança como o "movimento que leva da exigência prática ao postulado teórico", em termos "do pedido à espera". Há aqui uma relação intrigante entre espera e exigência, crença e obrigação, "hipótese existencial" e "necessidade moral", razão teórica e razão prática. Nessa relação, "a espera 'teórica' articula-se sobre a exigência 'prática'" (RICOEUR, 1988b, p. 410). A pressuposição central de tal articulação é que a esperança de completude é adicionada à consciência da obrigação. Em outras palavras, se fazemos o que está em nosso poder, uma outra fonte nos dará o que não está em nosso poder.

Embora Ricoeur (1988b, p. 410) saliente que "Kant não tem lugar para um conceito de dom", o pensador francês parece detectar no filósofo alemão um equivalente filosófico desse conceito. Nesse sentido, Ricoeur discerne uma significante aproximação entre a filosofia e a teologia, mais precisamente entre a filosofia dos limites e a hermenêutica da ressurreição, onde a esperança do dom exerce um papel preponderante.

\section{Esboço de uma perspectiva epistemológica da esperança}

Tendo em vista os subsídios teóricos apresentados nas seções anteriores, a presente seção procurará esboçar uma perspectiva epistemológica da esperança que sirva como horizonte para o pensamento filosófico e teológico. Para tanto, a seção se inicia com uma breve relação de Ricoeur com um filósofo da esperança e com um teólogo da esperança. Tanto o 
filósofo, Marcel, quanto o teólogo, Moltmann, já foram mencionados acima. A relação de Ricoeur com esses autores com respeito à compreensão da esperança fornece os contornos iniciais de como ele relaciona a esperança com a filosofia e com a teologia. Como se perceberá abaixo, a relação de Ricoeur com Moltmann terá uma extensão descritiva um pouco maior do que a da relação com Marcel. Essa diferença se justifica pelo fato de que teremos um pouco da voz de Moltmann nessa seção, que ainda não foi ouvida nesse artigo, ao passo que a voz de Marcel já teve o seu espaço na seção 1.1. Finalmente, a segunda parte da seção tratará de pontos fundamentais da perspectiva ricoeuriana para uma epistemologia da esperança enquanto horizonte filosófico e teológico.

\subsection{Ricoeur, Marcel e Moltmann: esperança, filosofia e teologia}

Uma comparação entre a descrição da filosofia da esperança em Marcel na seção $1.1 \mathrm{com}$ a compreensão ricoeuriana da esperança nas outras seções acima evidencia várias aproximações de Ricoeur em relação à filosofia de Marcel. À semelhança de Marcel, Ricoeur evita uma elaboração polarizada da esperança, se afastando de um vago otimismo e também de uma noção positivista de esperança que se esqueça dos limites da racionalidade. Ademais, a dimensão de triangulação temporal de Marcel, com o paralelo da relação de memória, atenção e expectativa em Temps et récit sublinham o caráter temporal da experiência humana no que diz respeito à compreensão da esperança. Considerando que a realidade do mal é, infelizmente, um traço presente no caráter temporal da experiência humana, a metáfora marceliana acerca da noite na qual se espera a luz que ainda não se vê pode ser usada para descrever a reflexão ricoeuriana da realidade do mal, em meio ao qual a luz da esperança é antevista. Nesse sentido, as trevas da noite são caracterizadas particularmente pela angústia, pelo temor, pela culpa, pelo sofrimento e pelo infortúnio. Uma relação marcadamente significativa, que será mais elaborada abaixo, é a temática da esperança enquanto visualização da dádiva, em contraste com uma espécie de demanda de direitos advinda de uma perspectiva contratual ou de obrigação que constitui para Marcel uma forma de profunda degradação da esperança.

Com respeito à aproximação teológica de Ricoeur em relação à Moltmann, estudiosos como Stewart (1970, p. 33, 49-52), Clawson (2013, p. 293-309) e Singh (2008, p. 251-269) enfatizam o profícuo relacionamento entre a teologia da esperança moltmanniana com a filosofia da esperança ricoeuriana. Se a reflexão da esperança em Ricoeur não se caracteriza particularmente por uma discussão conceitual do tema da esperança em si, mas no seu papel epistemológico como horizonte de um sistema de pensamento, algo similar pode ser dito da teologia da esperança de Moltmann. Conforme Gibellini (2002, p. 286) ressalta, essa teologia "não é um tratado específico sobre 
a esperança como virtude teologal". Isso significa que a esperança não é elaborada enquanto "objeto bem delimitado da reflexão teológica, mas é um ensaio de teologia escatológica, em que os temas centrais do cristianismo são revisitados na perspectiva da promessa, esperança e missão" (GIBELLINI, 2002, p. 286). Desse modo, tanto na filosofia da esperança de Ricoeur, quanto na teologia da esperança de Moltmann, a esperança é tratada mais como perspectiva ou horizonte do pensamento, do que como um tema específico.

Em segundo lugar, como indicado acima, Ricoeur enfatiza que o desespero é, de certo modo, uma atitude de esperança, no sentido de que ele é um ato cognitivo necessário que reconhece os limites do conhecimento, gerando uma abertura do sistema filosófico para o horizonte da esperança. Semelhantemente, a teologia da esperança de Moltmann interpreta o desespero como ato de esperança. Em suas palavras, "o desespero pressupõe esperança. 'Aquilo de que não temos desejo não pode ser objeto nem de nossa esperança, nem de nosso desespero' (Agostinho). A dor do desespero consiste precisamente em haver uma esperança" (MOLTMANN, 2005, p. 39).

Em terceiro lugar, a relação que Ricoeur procura estabelecer entre intellectus fidei e intellectus spei encontra paralelos com a teologia da esperança moltmanniana. Ao mencionar o princípio de Anselmo de Cantuária na Idade Média, "fides quaerens intellectum - credo ut intelligam [fé que examina o intelecto - creio para que entenda]", Moltmann (2005, p. 50) sublinha também o princípio "spes quaerens intellectum - espero para que entenda". Aliás, "não é a esperança que conserva a fé em vida, a sustenta e impele para frente? Não é a esperança que introduz o crente na vida de amor?" (MOLTMANN, 2005, p. 50). Desse modo, o teólogo alemão propõe que a esperança "mobiliza e impulsiona o pensamento da fé - o conhecimento e a reflexão sobre o ser do ser humano -, da história e da sociedade. O crente espera conhecer o que crê" (MOLTMANN, 2005, p. 50). Logo, o conhecimento teológico é "conhecimento antecipatório, fragmentário, que preludia o futuro prometido, apóia-se na esperança" (MOLTMANN, 2005, p. 50). Ao enfatizar o "intellectus fidei et spei [entendimento dado pela fé e pela esperança]", Moltmann (2005, p. 53) argumenta que "uma ação criadora a partir da fé é impossível sem um novo pensamento e uma nova projeção a partir da esperança". Fundamentada na fé, ela não representa uma "fuga da história", mas oferece "orientação à [...] existência" (KUZMA, 2009, p. 452).

Como Stewart (1970, p. 50) destaca, Moltmann demonstra teologicamente que a esperança é um conceito crucial da fé bíblica, e Ricoeur articula filosoficamente a noção de que a esperança é parte essencial da condição e da reflexão humana. Embora a articulação conceitual da esperança enquanto horizonte para a teologia e a filosofia possa encontrar limitações, 
é justamente na limitação da racionalidade e dos desafios da ausência de sentido que se abre o horizonte da paixão pelo possível.

\subsection{O horizonte epistemológico da esperança}

Um caminho potencialmente apropriado para introduzir a discussão de pontos fundamentais da perspectiva ricoeuriana para uma epistemologia da esperança enquanto horizonte de aproximação entre a filosofia e a teologia é o reconhecimento de que esse horizonte não reclama exclusividade com relação à expectativa do futuro. Em outras palavras, dada a ênfase de Ricoeur na ideia de temporalidade, formas de aproximação entre a filosofia e a teologia não precisam ter como foco exclusivo a expectativa do futuro. A princípio, seria possível sugerir aproximações com foco na memória (passado) e/ou em aspectos da situação presente. Por isso, a noção de horizonte epistemológico se projeta para o futuro, mas sem excluir a memória nem a situação imediata. Por outro lado, a ausência desse horizonte incorreria em pelo menos duas questões inter-relacionadas que parecem problemáticas para Ricoeur, a saber, a persistência do mal e o determinismo.

Considerando a reflexão ricoeuriana sobre a realidade histórica do mal, essa realidade perpassa temporalmente a memória como também a situação presente. É essencialmente a projeção futura dos olhos da esperança que vislumbra a superação das situações problemáticas do mal que marcam as memórias e as experiências atuais. Dito de outra maneira, é o horizonte da esperança, na medida em que privilegia a dimensão de expectativa do futuro, que permite alguma projeção de superação histórica do mal.

Deve-se reconhecer, no entanto, a existência de teorias alternativas que sugerem formas não históricas de superação do mal. Um exemplo dessas teorias dado por Ricoeur parece ser a filosofia do presente ou do agora, enfatizada na contemporaneidade por formas de existencialismo. Mas como Ricoeur também aponta, o existencialismo tende a ser marcado fortemente pela subjetividade individual e a filosofia do agora tem como nota tônica a suspeita de que o futuro não representa melhora. Nesse caso, ao invés de esperança, o futuro suscita desilusão. Na perspectiva ricoeuriana, essa visão deriva de uma noção de determinismo, que contempla um sistema fechado caracterizado pela necessidade, e que não tenho espaço para a irrupção do novo. Em outras palavras, na proposta de Ricoeur, é o horizonte da esperança, na medida em que privilegia a dimensão de expectativa do futuro, que permite alguma projeção de inovação histórica.

Se existe um conceito que tem o potencial de encapsular em alta intensidade a ideia de mal e a perspectiva do determinismo, este é provavelmente a realidade inegável da morte. Na morte se encontra a expressão histórica 
mais severa do mal e a asserção mais desafiadora do determinismo, que afirma ser a morte uma realidade irreversível. Por outro lado, vislumbrar a superação histórica do mal e contestar a primado do determinismo nos termos da inovação significa, em grau máximo, suplantar de algum modo a morte. Curiosamente, é precisamente aqui que Ricoeur encontra uma equivalência entre a teologia e a filosofia. Mais precisamente, entre a hermenêutica da ressurreição e a filosofia dos limites. Se na hermenêutica teológica está a promessa da ressurreição, na filosofia dos limites está o postulado prático da felicidade que aponta para a imortalidade. Nesse recorte ricoeuriano se encontra a esperança teológica e filosófica, articulada de acordo com as especificidades distintas dessas duas disciplinas, da superação da morte.

Na expectativa da superação do mal, o horizonte da esperança não apenas aguarda, mas atua como fissura dos sistemas fechados de pensamento e estimula uma reorganização do sentido da vida. Se a epistemologia determinista inibe, por assim dizer, qualquer pensamento acerca do que pode ser diferente do que parece ser necessário, a epistemologia da esperança abre as portas para a imaginação criativa do novo. Se a epistemologia determinista se caracteriza pela limitação, a epistemologia da esperança é retratada pela liberdade. Mas os termos "imaginação" e "limitação" precisam ser definidos com bastante cautela nessa discussão. A ideia de imaginação não tem aqui a conotação de fictício. Se tivesse, a imaginação criativa do novo estaria sendo definida pelo paradigma determinista, que com sua ênfase na necessidade excluiria qualquer possiblidade ontológica da irrupção do novo, no sentido de contingência.

No caso da ideia de limitação, como a perspectiva ricoeuriana pode acusar o paradigma determinista de ser limitativo e ao mesmo tempo afirmar uma filosofia dos limites? A resposta parece estar na crítica ricoeuriana de que o paradigma determinista pressupõe um sistema de pensamento de totalidade e de racionalidade absoluta. Nesse sentido, ele limita o que pode ser imaginado por afirmar categoricamente o que é impossível de acontecer. Mas esse tipo de racionalidade se esquece dos limites da razão. E é por isso que Ricoeur se simpatiza pela filosofia dos limites, que nega à razão uma atuação total e absoluta, abrindo um horizonte para a imaginação criativa do novo e do possível. Em seu combate ao determinismo, o pensador francês alia a esperança com a liberdade, isto é, um sistema aberto que privilegia a possibilidade ontológica da inovação.

Ao mesmo tempo, para evitar um otimismo ingênuo da esperança, Ricoeur esboça uma epistemologia da esperança com caráter dialético. Isso significa que as evidências da realidade do mal e da morte, enfatizados pelo paradigma determinista, não são ignorados nem minimizados pela epistemologia da esperança. Eles são reconhecidos, mas o outro polo da dialética é capaz de discernir sinais da irrupção criativa da vida, do 
novo. Nessa dialética, a realidade do mal e da morte é reconhecida, mas eles pronunciam a palavra final de uma realidade de necessidade por meio de uma lógica fechada da equivalência. Antes, os sinais da irrupção criativa do novo indicam que a lógica da necessidade e da equivalência se vale de uma racionalidade de totalidade e absolutismo, que não consegue dimensionar os sinais do novo que lhe escapa. De fato, o que é proposto nessa dialética ricoeuriana, por meio do polo de reconhecimento da liberdade do novo, é a abertura para o que vai além da racionalidade teórica.

Por isso, a ênfase na ideia de dom ressalta algo que é dado e que, portanto, vem de fora do sistema de pensamento racional. O que é externo à estrutura da racionalidade teórica não é capaz de ser capturado cognitivamente por uma contabilização racional. É por isso que o dom extrapola a lógica da equivalência de uma contabilização que promove a compreensão clara de um direito ou de uma obrigação, que se justifica dentro das articulações internas do sistema racional de pensamento. Assim, enquanto o determinismo se caracteriza pela lógica de uma racionalidade contábil que estabelece equivalências de um sistema interno de pensamento, o dom privilegia a liberdade do que é externo ao sistema de pensamento e que, em última instância, acaba subvertendo a lógica da equivalência. A partir de uma perspectiva dialética, essa subversão não elimina a lógica da equivalência. Ela apenas declara que essa lógica tem seus limites, e que ela acaba sendo excedida e pela realidade do dom. Essa é uma adição ou novidade que nos alcança e não pode ser capturada pela razão teórica, mas ela provoca uma demanda epistemológica de certa inteligibilidade e reorganização de sentido.

No caso da epistemologia da esperança no contexto do pensamento teológico, o polo dialético da irrupção do novo e da liberdade do dom se alinha bem ao conteúdo da fé, denominado por Ricoeur como kerygma da ressurreição, que é considerada a especificidade epistemológica da teologia. No entanto, esse conteúdo e proclamação não se caracterizam pela racionalidade de totalidade. Antes, o pensamento teológico discerne sinais da irrupção do novo, sem descartar a realidade vigente do mal. Esses sinais apontam para um dom que vem de fora. Mas sua compreensão não é absoluta e requer uma atitude de fé com relação às promessas bíblicas. Desse modo, o pensamento aguarda por uma compreensão mais ampla, na medida em que ele se projeta para o horizonte da esperança.

Com relação à epistemologia da esperança no contexto do pensamento filosófico, o polo dialético da irrupção do novo e da liberdade do dom não se articula na lógica da racionalidade teórica, que representa a especificidade epistemológica da filosofia. O que Ricoeur propõe a partir de apropriação da perspectiva kantiana é que essa racionalidade não é tudo na filosofia. Ela é um polo que se abre em relação dialética para um outro 
polo da razão prática que gera expectativas em relação à felicidade e a imortalidade proporcionados pelo dom da novidade que nos alcança. Com efeito, essas expectativas não são necessariamente contrárias aos postulados da razão teórica, quando essa razão está consciente de suas limitações e não assume a pretensão de totalidade.

\section{Considerações finais}

Essa breve investigação do caráter epistemológico da esperança como horizonte filosófico e teológico em Ricoeur delineou os traços básicos de uma aproximação epistemológica entre as articulações do pensamento teológico e as articulações do pensamento filosófico à luz do horizonte da esperança. As duas disciplinas lidam com a interpretação da realidade do mal e avaliam criticamente os paradigmas de uma perspectiva sistemática de cunho mais determinista e de uma perspectiva sistemática com maior ênfase na liberdade. Assim, em diálogo crítico com noções de necessidade e contingência na interpretação da realidade histórica, os campos da teologia e da filosofia podem sugerir projeções de expectativas em relação ao futuro. Embora as abordagens desses diferentes campos se definem de acordo com suas peculiaridades epistemológicas, Ricoeur propõe que ambos têm condições de articular suas reflexões tendo em vista o horizonte da esperança. Epistemologicamente, esse horizonte privilegia uma reflexão dialética que seja capaz de explorar a racionalidade, mas que esteja ao mesmo tempo atenta aos limites da razão e aberta para indícios de uma realidade que extrapola os contornos atuais da racionalidade, sem a presunção de que esses indícios sejam irracionais.

O significativo potencial epistemológico dessa discussão sugere que um aprofundamento da análise dessa proposta será benéfico para as relações entre a teologia e a filosofia. Além disso, como já indicado acima, considerando que a proposta ricoeuriana assume uma perspectiva de temporalidade, o caráter histórico desse paradigma epistemológico pode apontar não apenas para o futuro, na dimensão de um horizonte de esperança, mas também para o passado, nos termos da exploração da memória. Embora os conceitos investigados nesse artigo não indiquem que Ricoeur tenha sinalizado explicitamente na direção desse tipo de aproximação epistemológica da teologia e da filosofia, esse parece ser uma implicação do seu pensamento. Nessa perspectiva, futuros estudos dos textos ricoeurianos poderiam se debruçar no potencial da memória como elemento epistemológico de aproximação dessas duas disciplinas. Essa empreitada poderia revelar relevantes implicações para o horizonte epistemológico da esperança, na medida em que a memória se relaciona profundamente com a expectativa da esperança. 


\section{Referências}

ALBANO, P. J. Toward a Dialectical Apologetic of Hope: The Confrontive Dimension of Paul Ricoeur's Contribution to Fundamental Theology. Studies in Religion/ Sciences Religieuses, v. 15, n. 1, p. 77-88, Mar. 1986. Disponível em: <https://journals. sagepub.com/action/doSearch?SeriesKey=\&AllField=P.+J.+Albano\&SeriesKey=sira $>$. Acessado em: 13 ago. 2019.

BEATO, J. M. Da encarnação à esperança: as sendas comuns de Gabriel Marcel e Paul Ricoeur. PERI: Revista de Filosofia, Florianópolis, v. 6, n. 2, p. 113-137, Ago. 2014.

BERTMAN, M. A. Gabriel Marcel on Hope. Philosophy Today, Charlottesville (VA), v. 14, n. 2, p. 101-105, 1970. Disponível em: <https://www.pdcnet.org/philtoday/ content/philtoday_1970_0014_0002_0101_0105> . Acessado em 13 ago 2019.

BOURGEOIS, P. Hope at the Boundary of Reason: A Phenomenological, Philosophical and Theological Reflection. In: BLOECHL, J. et al. Phenomenology of Hope: The Twenty-first Annual Symposium of the Simon Silverman Phenomenology Center: Lectures. Pittsburgh, PA: Simon Silverman Phenomenology Center; Duquesne University-Gumberg Library, 2004. p. 28-41.

Hope, Imagination and Reflective Judgment: Paul Ricoeur and Immanuel Kant. In: ERFANI, F. (Org.). Paul Ricoeur: Honoring and Continuing the Work. Lanham, MD: Lexington, 2011. p. 119-133.

- Marcel and Ricoeur: Mystery and Hope at the Boundary of Reason in the Postmodern Situation. American Catholic Philosophical Quarterly, Charlottesville (VA), v. 80, n. 3, p. 421-433, Jun. 2006. Disponível em: <https://www.pdcnet.org/ collection-anonymous/browse?fp=acpq\&fq=acpq $\% 2 F V o l u m e \% 2 F 8907 \% 7 C 93 \% 2 F 89$ 97\%7CIssue\%3A\%203\%2F>. Acessado em: 13 ago. 2019.

CLAWSON, J. Imagination, Hope, and Reconciliation in Ricoeur and Moltmann. Anglican Theological Review, Sewanee, v. 95, n. 2, p. 293-309, Jan. 2013.

EINSOHN, H. I. Bernard Shaw and Paul Ricoeur: Emissaries of Hope, Faith, and Wellness. Shaw: The Journal of Bernard Shaw Studies, Pennsylvania, v. 34, n. 1, p. 133-161, Jan. 2014. Disponível em: <http://muse.jhu.edu/journal/180>. Acessado em: 13 ago. 2019.

FREITAS, M. B. C. G. Marcel: A dimensão metafísica da esperança. Revista Portuguesa de Filosofia, Braga, t. 45, n. 4, p. 531-548, Out./Dez. 1989.

GIBELLINI, R. A teologia do século XX. 2 ed. São Paulo: Loyola, 2002.

GODFREY, J. J. A Philosophy of Human Hope. Dordrecht, The Netherlands: Kluwer Academic Publishers, 1987.

HERNANDEZ, J. G. Gabriel Marcel's Ethics of Hope: Evil, God and Virtue. London; New York: Bloomsbury Academic, 2011.

HUSKEY, R. K. Paul Ricoeur on Hope: Expecting the Good. New York: Peter Lang, 2009.

KUZMA, C. A. A esperança cristã na 'teologia da esperança': 45 anos da teologia da esperança de Jürgen Moltmann: sua história, seu caminho, sua esperança. Revista Pistis \& Praxis: Teologia pastoral, Curitiba, v. 1, n. 2, p. 443-467, Jul./Dez. 2009. 
MARCEL, G. Homo Viator: prolégomènes à une métaphysique de l'espérance. Paris: Aubier; Montaigne, 1963.

MOLTMANN, J. Teologia da Esperança: Estudos sobre os fundamentos e as conseqüências de uma escatologia cristã. 3 ed. São Paulo: Loyola, 2005.

O'CALLAGHAN, P. La metafísica de la esperanza y del deseo en Gabriel Marcel. Anuario Filosófico, Navarra, v. 22, n. 1, p. 55-92, Jan. 1989.

PACHECO, M. L. Paul Ricoeur: A Esperança como movimento da existência no evento da ressurreição. 2017. 277f. Tese. (Doutorado em Filosofia) - Pontifícia Universidade Católica de São Paulo, São Paulo, 2017.

PLOURDE, S. Gabriel Marcel: Philosophe et témoin de l'esperance. Montréal: Les Presses de l'Université du Quebéc, 1975.

PORÉE, J. Gabriel Marcel et Paul Ricœur: une fidélité créatrice. In: HENRIQUES, F. (Org.). A filosofia de Paul Ricour: temas e percursos. Coimbra: Ariadne, 2006. p. 329-349.

RICOEUR, P. Le symbolique du mal. Paris: Aubier, 1960.

. Le conflit des interprétations. Essais d'herméneutique. Paris: Seuil, 1969.

. Hope and the Structure of Philosophical Systems. In: McLEAN, G.; DOUGHERTY, F. (Orgs.). Philosophy and Christian Theology. Washington: Proceedings of the American Catholic Philosophical Association, 1970. v. 44. p. 55-69.

. Temps et récit. Paris: Le Seuil, 1983. Tomo I.

. Lectures on Ideology and Utopia. New York: Columbia University Press, 1986a.

. Life: A Story in Search of a Narrator. In: DOESER, M.C.; KRAAY, J.N. (Orgs.). Facts and Values: Philosophical Reflections from Western and Non-Western Perspectives, Dordrecht: Martinus Nijhoff, 1986b. p. 121-132.

. The Symbolism of Evil. Boston: Beacon Press, 1986c.

. L'identité narrative. Esprit, Paris, v. 140/141, n. 7/8, p. 295-304, 1988a.

. O conflito das interpretações: ensaios de hermenêutica. Porto: Rés, 1988b.

. Tempo e narrativa. Campinas: Papyrus, 1994. Tomo I.

. Lamentação como prece. In: RICOEUR, P.; LaCOCQUE, A. Pensando biblicamente. Bauru: EDUSC, 2001. p. 233-254.

. A memória, a história, o esquecimento. Campinas: Editora da Unicamp, 2007. . A hermenêutica bíblica. São Paulo: Loyola, 2017.

SANTOS, J. P dos. A esperança em Gabriel Marcel. Revista Portuguesa de Filosofia, Braga, t. 21, n. 4, p. 380-401, Out./Dez. 1965.

SINGH, D. Resurrection as surplus and possibility: Moltmann and Ricoeur. Scottish Journal of Theology, Cambridge, v. 61, n. 3, p. 251-269, Aug. 2008. 
STEWART, D. In Quest of Hope: Paul Ricoeur and Jürgen Moltmann. Restoration Quaterly, Abilene, v. 13, p. 31-52, Jan. 1970.

TIAHA, D. L. Critique de la fin promise. Esquisse d'une herméneutique processionnelle du sujet avec Ricœur. Études théologiques et religieuses, Montpellier, t. 92, n. 2, p. 433-459, Avril 2017.

VANHOOZER, K. J. Biblical Narrative in the Philosophy of Paul Ricoeur. Cambridge: Cambridge University Press, 1990.

. The Joy of Yes: Ricoeur: Philosopher of Hope. The Christian Century, Chicago, v. 122, n. 17, p. 27-28, Aug. 2005.

WHITE, E. Between Suspicion and Hope: Paul Ricoeur's Vital Hermeneutic. Journal of Literature and Theology, Oxford, v. 5, n. 3, p. 311-321, Nov. 1991.

Artigo submetido em 07.06.2018 e aprovado em 10.08.2019.

Adriani Milli Rodrigues é doutor em Teologia pela Andrews University, EUA, (2017), mestre em Ciências da Religião pela Universidade Metodista de São Paulo - UMESP (2009), e professor de Teologia sistemática na Faculdade de Teologia do Centro Universitário Adventista de São Paulo - UNASP. Orcid.org/0000-0002-1812-8622. E-mail: adriani.milli@unasp.edu.br

Endereço: Rua Arara 99, Recanto dos Pássaros

Engenheiro Coelho - SP

CEP 13.445-970 Caixa Postal 131 